\title{
Maternal influence on timing of parturition, fecundity, and larval quality in three shelf rockfishes (Sebastes spp.)
}

\author{
David M. Stafford ${ }^{1,2, *}$, Susan M. Sogard ${ }^{2}$, Steven A. Berkeley ${ }^{3}$ \\ ${ }^{1}$ Moss Landing Marine Laboratories, Moss Landing, California 95039, USA \\ ${ }^{2}$ Fisheries Ecology Division, Southwest Fisheries Science Center, National Marine Fisheries Service, NOAA, Santa Cruz, \\ California 95060, USA \\ ${ }^{3}$ University of California Santa Cruz, Santa Cruz, California 95060, USA
}

\begin{abstract}
Differences in maternal investment and reproductive timing can have important consequences for offspring survival. Prior studies on nearshore rockfishes have shown significant effects of maternal age and size on the timing of parturition, fecundity, and larval quality, offering advantages to population persistence by maintaining age diversity in rockfish populations. In this study, reproduction in chilipepper Sebastes goodei, widow rockfish $S$. entomelas, and yellowtail rockfish $S$. flavidus was examined to determine whether age- and size-related effects on maternal investment and reproductive timing are exhibited in deeper-dwelling species of this genus. Parturition dates were derived from fine-scale staging of pre-parturition embryos from gravid females. Measurements of embryonic energy reserves (oil globule and yolk), indicators of condition, were used to estimate depletion rates and to test for maternal age and size effects on larval quality. For widow and yellowtail rockfish, larger or older rockfish gave birth earlier in the parturition season than younger, smaller fishes. Maternal factors of weight, length, or age were positively correlated to absolute and relative (weight-specific) fecundity in all species. A trade-off was observed between egg size and fecundity among species, with chilipepper displaying larger egg size and lower fecundity relative to widow and yellowtail rockfish. Embryonic reserves were weakly but significantly related to age only in chilipepper, with embryos from larger, older mothers having larger oil globules. Since the strength of maternal effects varies among Sebastes species, information on maternal influence can assist managers in identifying species most likely to benefit from the protection of age structure afforded by marine reserves or other fisheries regulations.
\end{abstract}

KEY WORDS: Sebastes $\cdot$ Maternal effects $\cdot$ Larval quality $\cdot$ Timing of parturition $\cdot$ Fecundity

\section{INTRODUCTION}

The commercial, recreational, and ecological importance of rockfishes Sebastes spp. merit additional early life history research to understand factors determining their recruitment success or failure. Knowledge of species-specific reproductive phenologies and factors determining both the quality and quantity of offspring is integral to evaluating

\footnotetext{
*Corresponding author: david.stafford@noaa.gov
}

reproductive success. All nearshore Sebastes species researched to date have exhibited some significant effect of maternal size or age on reproductive traits (Berkeley et al. 2004a, Bobko \& Berkeley 2004, Fisher et al. 2007, Sogard et al. 2008, Rodgveller et al. 2012). This study extends our understanding of maternal effects to deep-water rockfishes, examining the timing of parturition, fecundity, and larval quality.

() The authors 2014. Open Access under Creative Commons by Attribution Licence. Use, distribution and reproduction are unrestricted. Authors and original publication must be credited. 
Rockfishes are among the longest-lived marine fishes along the Pacific coast (Cailliet et al. 2001) and do not display reproductive senescence (de Bruin et al. 2004). All Sebastes spp. are live-bearers and can mate several months prior to egg fertilization. Females have the ability to store sperm, control fertilization, and ultimately determine the timing of parturition (Love et al. 2002). Offspring develop and hatch within the ovaries synchronously. Species north of central California typically extrude 1 brood per year, whereas some southern populations may have an additional brood (MacGregor 1970, Wyllie Echeverria 1987, Love et al. 2002). Gestation period ranges from 1 to $2 \mathrm{mo}$, with a longer duration in colder temperatures. At birth, larvae are free-swimming and able to begin exogenous feeding in their pelagic environment. High fecundity and typically long reproductive lifespan in rockfishes serve as a bethedging strategy to buffer against high variability in recruitment success in the physically dynamic environment of the Northeast Pacific (Leaman \& Beamish 1984, Longhurst 2002).

An age/size-related maternal effect on the timing of parturition potentially provides a stabilizing influence on recruitment during periods of poor environmental conditions. In some rockfishes, older females extrude larvae earlier in the season than younger females, effectively extending the parturition season (Nichol \& Pikitch 1994, Bobko \& Berkeley 2004, Sogard et al. 2008, Rodgveller et al. 2012). This protracted parturition season results in a greater likelihood of larval production during times of peak food availability, as in the match-mismatch hypothesis (Cushing 1990). Sogard et al. (2008) suggest that a progression of earlier parturition dates with increasing female age represents a diversified bet-hedging strategy, effectively spreading annual reproductive effort over time within a maternal lineage despite the constraint of each individual spawning only once each year.

In some nearshore rockfishes, older mothers provide greater nutrient reserves to their offspring compared to younger mothers (Berkeley et al. 2004a, Sogard et al. 2008, Rodgveller et al. 2012). During embryonic development, each larva is provisioned with endogenous energy in the form of yolk containing an oil globule (see Fig. 1) comprised of triacylglycerol lipids (Norton \& MacFarlane 1999). At parturition, larvae have absorbed their yolk, but a portion of their oil globule remains, sustaining the larvae after extrusion until they are able to locate prey and feed (Fisher et al. 2007). In laboratory experiments, rockfish larvae from older, larger mothers had larger oil globules and exhibited increased resistance to starvation compared to larvae from younger, smaller mothers (Berkeley et al. 2004a, Sogard et al. 2008).

In many teleosts, absolute fecundity (total number of eggs produced), often used as a proxy for reproductive success, typically increases as maternal size increases (Blaxter 1969, Love et al. 2002). In rockfishes, older, larger females also exhibit increased relative fecundity (number of eggs produced per gram of female body weight), thereby contributing more larvae per unit biomass than younger females (Boehlert et al. 1982, Bobko \& Berkeley 2004, Sogard et al. 2008). The strength of this maternal effect on fecundity varies among species of Sebastes (Dick 2009). In long-term studies, interannual differences have been found in the fecundities of young $(<15 \mathrm{yr}$ old) yellowtail rockfish (Eldridge \& Jarvis 1995). Older yellowtail, however, were less affected by environmental influences, thus further demonstrating the role older fishes play in stabilizing populations during poor environmental conditions.

Stock assessment models have assumed constant relative fecundity among mature females such that annual egg production is directly proportional to the population's spawning stock biomass regardless of age or size structure (Berkeley 2006, Dick 2009). For species displaying age- and size-modulated differences in fecundity and larval quality, the assumption of equivalent relative fecundity can result in a misestimation of population productivity. Increasing recognition of the disproportionate contribution of larger, older females to fecundity has resulted in the incorporation of maternal effects in assessments for some but not all Sebastes species. Larval quality differences among mothers have received less recognition, although modeling studies suggest that their inclusion may improve estimates of recovery time for overfished populations (Lucero 2008, 2009) and stock productivity (Spencer \& Dorn 2013).

This study investigates whether age- and sizerelated effects in maternal investment and reproductive timing are exhibited in deeper-dwelling species of this genus (chilipepper Sebastes goodei and widow rockfish $S$. entomelas). In prior studies (Berkeley et al. 2004a, Sogard et al. 2008), gravid females of nearshore species were held in laboratory tanks until parturition, allowing the precise measurement of larval traits upon completion of development. However, many species that live in deeper habitats are more susceptible to barotrauma-related injuries when brought to the surface, making laboratoryrearing studies impractical. Our approach here was to use fine-scale developmental staging to determine 
maternal effects on the oil globule depletion rate during embryogenesis and to predict parturition date.

Yellowtail rockfish $S$. flavidus are included in this study to compare methodologies for the prediction of parturition timing, larval quality, and fecundity. Although they are a shelf species, yellowtail rockfish migrate vertically to feed (Pereyra et al. 1969, Pearcy 1992) and, in contrast to most Sebastes species, can purge their swim bladders quickly upon ascent (Love et al. 2002), reducing barotrauma-related injuries. Adult females have successfully been held in the laboratory until parturition, allowing the assessment of larval quality, timing of parturition, and fecundity (Eldridge et al. 2002, Fisher et al. 2007, Sogard et al. 2008). Results from laboratory studies of yellowtail rockfish are compared with predictions made from preparturition yellowtail rockfish embryos in this study.

\section{MATERIALS AND METHODS}

\section{Sampling}

Gravid female chilipepper, widow, and yellowtail rockfishes were collected via hook and line fishing at 150 to $400 \mathrm{~m}$ depth from Cordell Bank, California (approximate location $38.0666^{\circ} \mathrm{N}, 123.3678^{\circ} \mathrm{W}$ ) from
2005 through 2008 (Table 1). All 3 species give birth in the winter (Table 2, Wyllie Echeverria 1987, Love et al. 2002); thus, sampling began in December and continued bi-weekly, weather permitting, through March or until fish with developing embryos were no longer found. Morphometric data collected from each adult included fork length, total weight, ovary weight, and somatic weight (total weight minus ovary weight).

Sagittal otoliths were extracted from each adult to obtain maternal age data. Age validation has been conducted by marginal increment analysis on all 3 species: yellowtail rockfish (Leaman \& Nagtegaal 1987), widow rockfish (Lenarz 1987), and chilipepper (J. Mello pers. comm.). It was therefore assumed that all study species deposit annual growth band pairs, composed of 1 opaque and 1 translucent band (Cailliet et al. 2006), which were counted for age estimates. Otoliths were prepared using the break and burn method (Beamish \& Chilton 1982, Laidig et al. 2003), which is routinely used for rockfish stock assessments.

\section{Embryonic staging/timing of parturition}

Upon dissection, each fish was assigned a macroscopic maturity stage (Table 3, Gunderson et al.

Table 1. Collection summary reporting sample size and fork length, weight, and age means $( \pm \mathrm{SD})$ and ranges for study species during collection winters 2005/2006 to 2007/2008 in Cordell Bank, CA. na = not available

\begin{tabular}{|c|c|c|c|c|c|c|c|}
\hline \multirow[t]{2}{*}{ Year/species } & \multirow[t]{2}{*}{$\mathrm{n}$} & \multicolumn{2}{|c|}{ Fork length (mm) } & \multicolumn{2}{|c|}{ Weight $(g)$} & \multicolumn{2}{|c|}{ Age (yr) } \\
\hline & & Mean \pm SD & Range & Mean \pm SD & Range & Mean $\pm \mathrm{SD}$ & Range \\
\hline \multicolumn{8}{|l|}{$2005 / 2006$} \\
\hline Widow rockfish & 91 & $428 \pm 36$ & $324-489$ & $1170 \pm 286$ & $463-1775$ & $12 \pm 4$ & $5-22$ \\
\hline Yellowtail rockfish & 144 & $419 \pm 29$ & $320-505$ & $1101 \pm 201$ & $475-1782$ & $14 \pm 4$ & $6-27$ \\
\hline Chilipepper & 316 & $416 \pm 30$ & $290-515$ & $1004 \pm 215$ & 458-1799 & $8 \pm 3$ & $5-23$ \\
\hline \multicolumn{8}{|l|}{$2006 / 2007$} \\
\hline Widow rockfish & na & & & & & & \\
\hline Yellowtail rockfish & na & & & & & & \\
\hline Chilipepper & 53 & $407 \pm 14$ & $363-435$ & $903 \pm 100$ & $610-1106$ & $7 \pm 1$ & $6-9$ \\
\hline \multicolumn{8}{|l|}{$2007 / 2008$} \\
\hline Widow rockfish & 66 & $429 \pm 29$ & $382-482$ & $1182 \pm 217$ & $859-1627$ & $13 \pm 5$ & $7-27$ \\
\hline Yellowtail rockfish & na & & & & & & \\
\hline Chilipepper & 38 & $435 \pm 29$ & $386-502$ & $1109 \pm 221$ & $387-1593$ & $12 \pm 4$ & $8-26$ \\
\hline
\end{tabular}

Table 2. Parturition period, community, and life history traits for rockfishes in this study

\begin{tabular}{|lccccc|}
\hline Species & $\begin{array}{c}\text { Parturition } \\
\text { period }^{\mathrm{a}}\end{array}$ & Community & $\begin{array}{c}\text { Longevity }^{\mathrm{b}, \mathrm{c}} \\
\text { (yr) }\end{array}$ & $\begin{array}{c}\text { Length at } \\
\text { maturity }^{\mathrm{b}} \text { (mm) }\end{array}$ & $\begin{array}{c}\text { Maximum } \\
\text { length }^{\mathrm{b}} \text { (mm) }\end{array}$ \\
\hline Widow rockfish & Dec-Apr & Shelf & 60 & $350-380$ & 590 \\
Yellowtail rockfish & Jan-July & Shelf & 64 & $360-450$ & 660 \\
Chilipepper & Nov-Mar & Deep shelf & 35 & 340 & 590 \\
${ }^{a}$ Wyllie Echeverria (1987); ${ }^{\mathrm{b}}$ Love et al. (2002); ${ }^{c}$ Cailliet et al. (2001) & & & \\
\hline
\end{tabular}


Table 3. Macroscopic descriptions of stages used to describe female widow rockfish, yellowtail rockfish, and chilipepper ovarian development (Gunderson et al. 1980, Bobko \& Berkeley 2004)

\begin{tabular}{|ll|}
\hline Maturity stage & Macroscopic description \\
\hline 2 Immature & $\begin{array}{l}\text { Ovary small and translucent or small } \\
\text { and yellow. } \\
\text { Ovary firm, eggs yellowish and } \\
\text { opaque. Widow rockfish eggs are } \\
\text { cream in color. }\end{array}$ \\
Eg Fertilization & $\begin{array}{l}\text { Eggare golden and translucent. } \\
\text { Ovary extremely large in relation to } \\
\text { body cavity. Ovary wall thin and } \\
\text { easily torn. } \\
\text { Eyes of developing embryos visible, } \\
\text { giving ovary an overall greyish color. } \\
\text { Ovary fills a large portion of the body } \\
\text { cavity. } \\
\text { Ovary flaccid, purplish-red in color. } \\
\text { Eyed larvae may still be visible. }\end{array}$ \\
\hline
\end{tabular}

1980, Bobko \& Berkeley 2004). Frequency histograms of stage by collection month were created to provide a coarse-scale assessment of differences in the timing of ovarian development during the reproductive season based on maternal size (in $20 \mathrm{~mm}$ bins). For finer scale analyses, samples of fertilized eggs and developing larvae were photographed using a Nikon dissection microscope equipped with a high-resolution calibrated camera. Larvae were assigned one of 33 developmental stages, each corresponding to an estimated number of days to birth, according to the classification scheme for kurosoi Sebastes schlegeli (Yamada \& Kusakari 1991, Table 4, Fig. 1). Gestation time was modified using a conversion formula developed by Eldridge et al. (2002) $\left(\mathrm{r}^{2}=0.94\right)$ for yellowtail rockfish also captured on Cordell Bank:

Days to parturition $=-0.022 x^{2}-0.097 x+28.9$

where $x=$ developmental stage following the Yamada \& Kusakari (1991) scheme. Under laboratory conditions at $12.0^{\circ} \mathrm{C}$, the yellowtail rockfish in Eldridge et al.'s (2002) study had a mean gestation period of $29.2 \mathrm{~d}$ (range 27 to $33 \mathrm{~d}$ ).

Chilipepper and widow rockfish larvae were assumed to follow a similar time course of development under the same temperature regime. Mean sea surface temperatures in the Cordell Bank area ranged from 10.5 to $13.0^{\circ} \mathrm{C}$ during our collections, suggesting that $12^{\circ} \mathrm{C}$ provided a reasonable approximation of the temperatures experienced by female rockfish during the well-mixed, pre-upwelling conditions of the winter spawning period.
Table 4. Fine-scale embryonic staging (Yamada \& Kusakari 1991), with converted developmental timing (Eldridge et al. 2002) for yellowtail rockfish. Refer to Fig. 1 for a visual representation of embryonic stages

\begin{tabular}{|c|c|c|}
\hline $\begin{array}{l}\text { Yamada/ } \\
\text { Kusakari } \\
\text { stage }\end{array}$ & $\begin{array}{l}\text { Developmental stage } \\
\text { description }\end{array}$ & $\begin{array}{l}\text { Eldridge } \\
\text { et al. time } \\
\text { to birth (d) }\end{array}$ \\
\hline 1 & Mature unfertilized ovum & \\
\hline 2 & Formation of the germ disc & 29 \\
\hline 3 & 2-celled ovum & \\
\hline 4 & 4-celled ovum & \\
\hline 5 & 8-celled ovum & \\
\hline 6 & 16-celled ovum & \\
\hline 7 & 32-celled ovum & \\
\hline 8 & 64-celled ovum & \\
\hline 9 & Morula & 26 \\
\hline 10 & Early blastula & \\
\hline 11 & Late blastula & \\
\hline 12 & Beginning of epiboly & \\
\hline 13 & Early gastrula & 24 \\
\hline 14 & Late gastrula & \\
\hline 15 & Embryonic shield & \\
\hline 16 & Head fold & 22 \\
\hline 17 & Optic vesicles & \\
\hline 18 & Somite formation begins & \\
\hline 19 & Finfold & \\
\hline 20 & Optic cups and auditory vesicle & 18 \\
\hline 21 & Auditory placodes & \\
\hline 22 & Lens formation, motility & \\
\hline 23 & Appearance of otoliths & \\
\hline 24 & Pectoral fins & \\
\hline 25 & Retinal pigmentation & 11 \\
\hline 26 & Blood circulation & \\
\hline 27 & Lens transparent & \\
\hline 28 & Mouth and anus open & 8 \\
\hline 29 & Pigmentation of the peritoneal wall & \\
\hline 30 & Depletion of yolk & \\
\hline 31 & Pre-hatching & 6 \\
\hline 32 & Hatching & \\
\hline 33 & Hatched, pre-born larva & 0 \\
\hline
\end{tabular}

To calculate parturition date, the estimated number of days to parturition was added to the capture date for each mother. Regression analyses (ordinary least squares, OLS) were used to determine if there were age- or size-related maternal influences on the timing of parturition in each species. Results for yellowtail rockfish were compared with those previously observed for fish held in laboratory tanks until larval release (Sogard et al. 2008).

\section{Fecundity}

The gravimetric method (Bagenal \& Braum 1978) was used for fecundity analyses. Fecundity estimates 


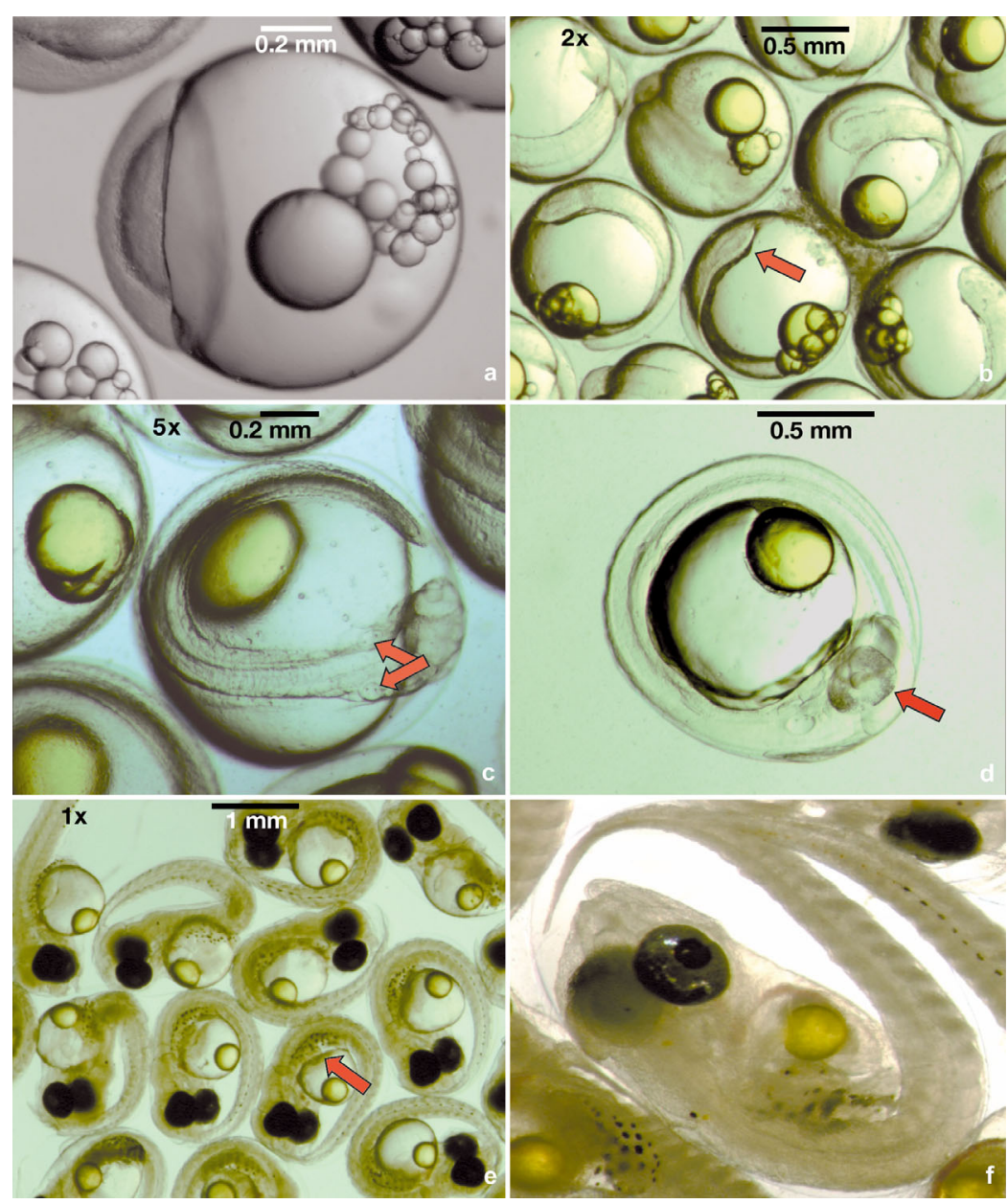

Fig. 1. Examples of embryonic features (highlighted by arrows) used in fine-scale staging of developing chilipepper embryos: (a) late blastula (stage 11), (b) head fold (stage 16), (c) appearance of otoliths (stage 23), (d) pigmentation of retina (stage 25), (e) pigmentation of peritoneal wall (stage 29), and (f) pre-hatching (stage 31). Note the oil globule surrounded by clear yolk in (d)

were obtained by counting all of the eggs/larvae in each of 2 weighed subsamples ( 0.5 to $1 \mathrm{~g}$ ) per mother and scaling by total ovary weight. The 2 fecundity estimates were averaged to determine total fecundity for each fish.

Relative fecundity was determined by dividing the total fecundity by somatic weight, providing a standardized measure to compare fish of different sizes. Regression analyses (OLS) were used to determine if there were age- or size-related maternal effects on relative fecundity in each species. Data from previous laboratory studies on yellowtail rockfish relative fecundity at parturition (Sogard et al. 2008) were compared with predicted values from pre-parturition samples.

\section{Egg size comparison among species}

A calibrated pen tablet (Wacom Technology) was used to measure the circumference of fertilized eggs in stages $<22$ (lens formation) from embryos of each species. These stages were chosen to confine measurements to early development, when eggs remain spherical. ANCOVA was used to determine if there were differences in egg size among species, with stage and maternal size (fork length) as covariates. The relationship between egg size and relative fecundity was compared among species at a standardized size of $450 \mathrm{~mm}$ fork length.

\section{Larval quality}

Mean oil globule volumes from each developing brood of larvae were used to determine the oil utilization rate during gestation for each species. Optimas image analysis software (version 6.51) was used to measure the oil globule volume $\left(\mathrm{mm}^{3}\right)$ from 5 to 20 randomly subsampled embryos from each female. The average coefficient of variation for measurements within a female's brood was less than $5 \%$. Since meristics from photographs only offer 2-dimensional viewing, oil globule volumes, assumed to be spherical, were obtained by averaging 2 diameter measurements and calculating the volume for a sphere, $V=(4 / 3) \pi r^{3}$. Embryonic yolk utilization rates were also determined using photomicrographs. For the non-spherical yolk sac, a proxy for size was obtained by tracing the circumference of the yolk using a calibrated pen tablet and subtracting the enclosed oil globule circumference.

A regression (OLS) of oil globule volume versus embryonic developmental time to parturition (derived from fine-scale staging as noted above) was used to examine the rate of oil depletion for each species. Models were selected by choosing the regression with the highest coefficient of determination. The residuals of measured oil volumes from this regression were examined to determine if there was a relationship with maternal age and size. Data from previously published laboratory studies on yellowtail 

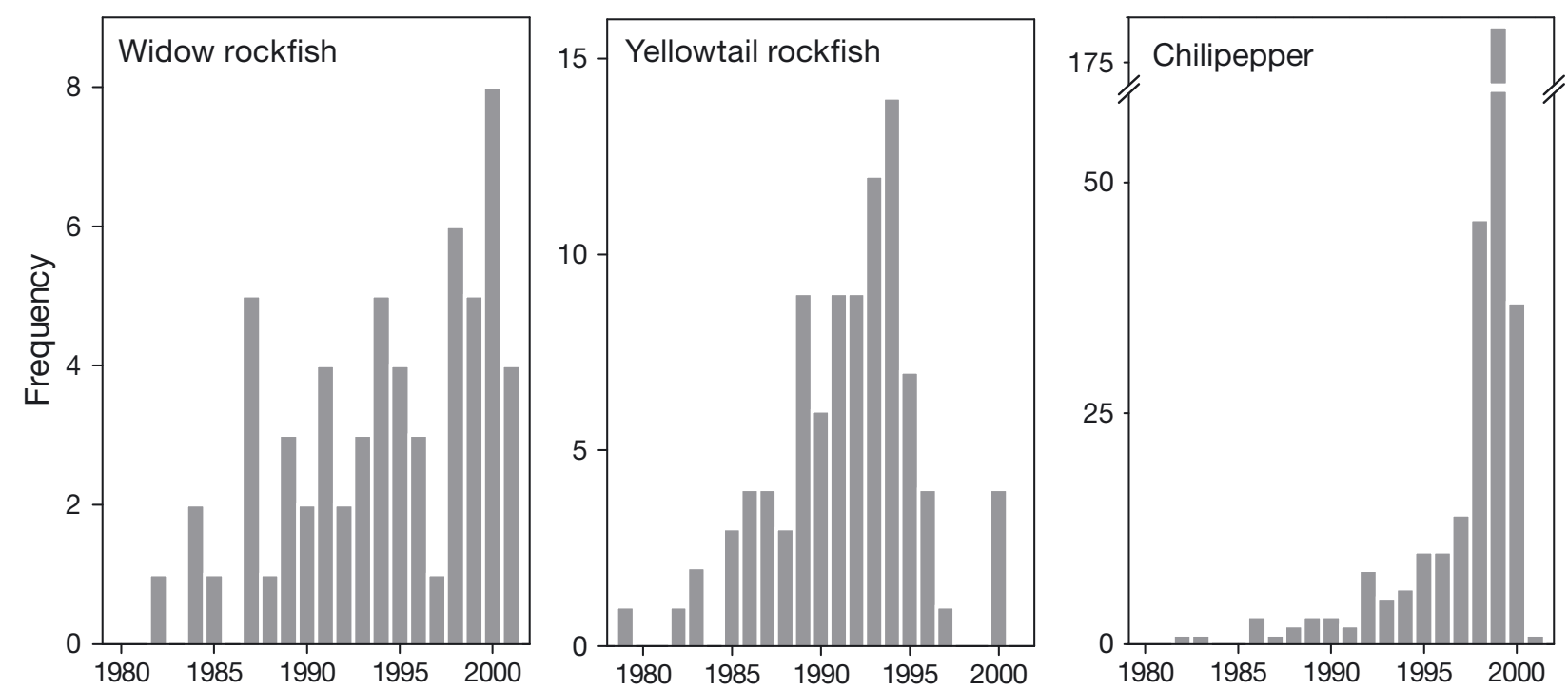

Fig. 2. Year class histogram based on otolith ages of adult female rockfishes collected at Cordell Bank, all collection years combined. Note break in scale for chilipepper

a) Widow rockfish

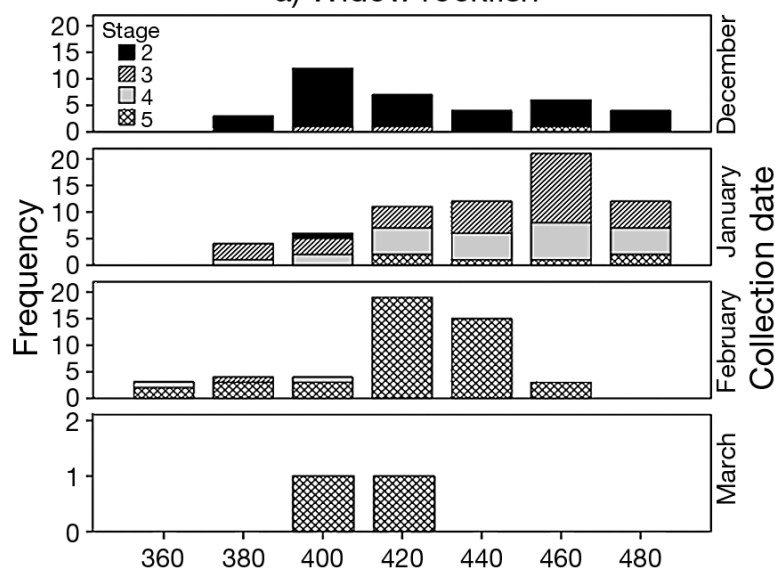

b) Yellowtail rockfish

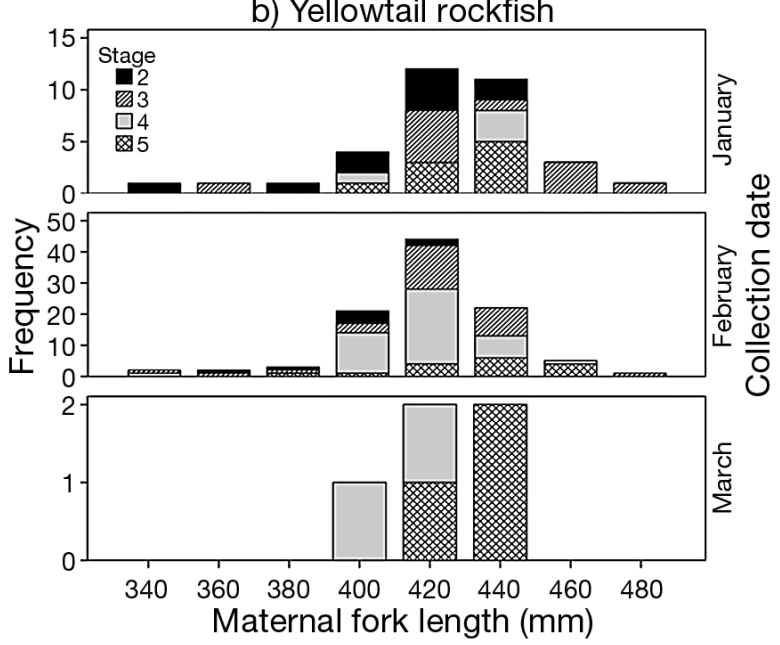

c) Chilipepper

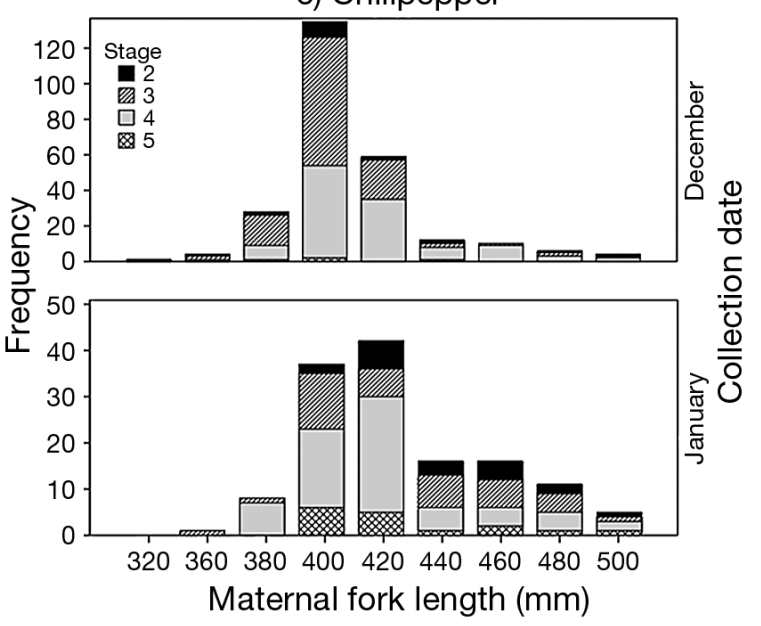

Fig. 3. Histogram of macroscopic ovarian development in (a)widow rockfish, (b) yellowtail rockfish, and (c) chilipepper binned in $20 \mathrm{~mm}$ increments, by month of collection throughout the parturition season, sampling years combined (except for yellowtail rockfish). Stage descriptions are as follows: stage 2 (unfertilized), stage 3 (newly fertilized), stage 4 (eyed larvae) and stage 5 (spent) 
rockfish oil globule volume at parturition (Sogard et al. 2008) were compared with the observed relationship in this study.

IBM SPSS Statistics (v.19) software was used for all statistical analyses in this study. ANOVAs and linear regressions were performed following verification of the assumptions of normality and homoscedasticity of variance. Preliminary analyses found no interannual differences for any of the response variables; therefore, collection years were pooled.

\section{RESULTS}

\section{Collection summary}

A broad age and size range of each species was collected (Table 1). Based on female ages derived from otoliths, the proportion of fish in each year class (year of birth) was determined. Chilipepper ranged in age from 5 to 26 yr but were clearly dominated by the 1999 year class (Fig. 2). Yellowtail rockfish ranged from 6 to 27 yr of age. The 1994 year class was most abundant but did not strongly dominate the population, as observed for the 1999 year class of chilipepper. Widow rockfish ranged in age from 5 to $27 \mathrm{yr}$, with the 2000 year class most abundant but, as with yellowtail, not clearly dominant within the population.

\section{Timing of parturition}

\section{Macroscopic staging}

Based on macroscopic staging, larger widow rockfish females appeared to fertilize their eggs and initiate embryo development earlier in the parturition season than smaller fish (Fig. 3a). In December, the majority of widow rockfish had unfertilized eggs, whereas a few larger fish (460 mm bin) were already spent. In January, larger fish (420 to $480 \mathrm{~mm}$ bins) were further along in ovarian development, with some spent individuals, but none of the smaller size classes $(<420 \mathrm{~mm})$ were spent. By February, the largest fish in the collection were spent, but some smaller fish (360 to $400 \mathrm{~mm}$ ) were still developing larvae.

Macroscopic staging of yellowtail rockfish suggested that larger females extruded larvae earlier in the parturition season (Fig. 3b). In January and February, smaller fish (340 to $440 \mathrm{~mm}$ ) in the collection had unfertilized eggs or newly fertilized larvae, whereas the majority of the largest fish (>440 mm) were spent.
In chilipepper, macroscopic staging suggested a weak trend of the reverse pattern, with larger fish somewhat delayed in parturition timing compared to smaller fish (Fig. 3c). In December, both small and large chilipepper were represented by all stages. In January, a higher proportion of larger fish (>400 mm) were earlier in development, at stages 2 and 3, compared to smaller fish $(<420 \mathrm{~mm})$.

Fine-scale staging

For widow rockfish with developing embryos (macroscopic stages 3 and 4), larger, older females released larvae earlier in the season than smaller, younger fish (Fig. 4). Maternal factors of length, weight, and age were all significantly related to parturition date (linear regression with length: $F_{1,58}=18.393$, $\mathrm{p}<0.001, \mathrm{r}^{2}=0.24$, with weight: $F_{1,58}=21.794, \mathrm{p}<0.001$, $\mathrm{r}^{2}=0.28$, with age: $F_{1,58}=6.144, \mathrm{p}=0.016, \mathrm{r}^{2}=0.08$ ).

Yellowtail rockfish displayed a similar pattern to widow rockfish, with larger, older females giving birth earlier in the parturition season (Fig. 4, linear regression with length: $F_{1,93}=11.534, \mathrm{p}=0.001, \mathrm{r}^{2}=$ 0.10 , with weight: $F_{1,92}=22.882, \mathrm{p}<0.001, \mathrm{r}^{2}=0.19$, with age $F_{1,92}=7.496, \mathrm{p}=0.007, \mathrm{r}^{2}=0.08$ ). Yellowtail rockfish held in laboratory tanks until parturition (Sogard et al. 2008) showed a similar significant trend, with larger females releasing larvae earlier in the season than smaller females $\left(n=36, r^{2}=0.50\right)$.

Chilipepper displayed unusual residual patterns from the linear regression between estimated parturition date and age or size; thus, parametric statistical analyses were not possible. Younger fish released larvae throughout the season, whereas older fish showed a bimodal trend in the timing of parturition (Fig. 4).

\section{Fecundity}

Absolute fecundity

Absolute fecundity for widow rockfish ranged between 39585 and 734732 larvae per mother and increased with maternal weight, length, and age (Fig. 5a). The highest correlation for the relationship was linear for maternal weight $\left(F_{1,53}=45.077, \mathrm{p}<\right.$ $\left.0.001, \mathrm{r}^{2}=0.46\right)$, a power function for maternal length $\left(F_{1,53}=55.053, \mathrm{p}<0.001, \mathrm{r}^{2}=0.51\right)$, and logarithmic for maternal age $\left(F_{1,53}=18.306, \mathrm{p}<0.001, \mathrm{r}^{2}=0.26\right)$.

In yellowtail rockfish, absolute fecundity ranged between 64824 and 720113 larvae per mother (Fig. 5b). The highest correlation for the relationship was lin- 

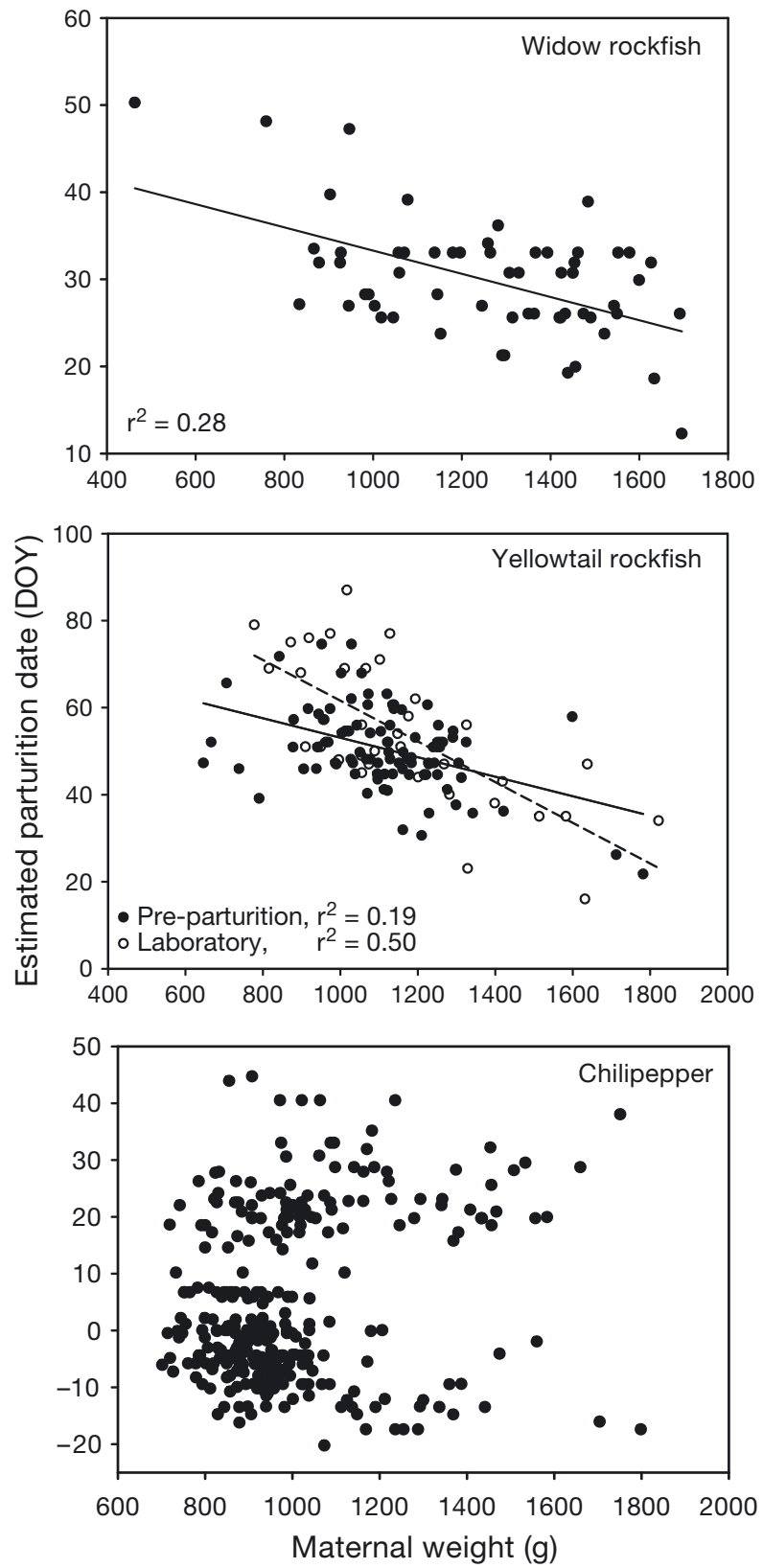

Fig. 4. Maternal influence on parturition date for widow rockfish, yellowtail rockfish, and chilipepper. Each symbol shows the estimated parturition date (day of the year [DOY], 1 = January 1) for the brood of 1 female, based on fine-scale staging of embryos. The maternal factor (age, length, or weight) with the strongest relationship with extrusion date is displayed. Dashed line in (b) presents yellowtail rockfish data from laboratory studies for comparison (Sogard et al. 2008)

ear for maternal weight $\left(F_{1,91}=60.474, \mathrm{p}<0.001, \mathrm{r}^{2}=\right.$ $0.40)$, a power function for maternal length $\left(F_{1,91}=\right.$ 43.896, $\left.\mathrm{p}<0.001, \mathrm{r}^{2}=0.33\right)$, and logarithmic for maternal age $\left(F_{1,90}=11.693, \mathrm{p}=0.001, \mathrm{r}^{2}=0.12\right)$.

In chilipepper, absolute fecundity increased significantly with maternal size and age and ranged be- tween 79382 and 488119 larvae per mother (Fig. 5c). The highest correlation for the relationship was linear for maternal weight $\left(F_{1,171}=354.478, \mathrm{p}<0.001\right.$, $\left.\mathrm{r}^{2}=0.74\right)$, a power function for maternal length $\left(F_{1,171}=\right.$ $\left.321.679, \mathrm{p}<0.001, \mathrm{r}^{2}=0.65\right)$, and logarithmic for maternal age $\left(F_{1,171}=254.223, \mathrm{p}<0.001, \mathrm{r}^{2}=0.60\right)$.

\section{Relative fecundity}

After adjusting for maternal size by dividing absolute fecundity by female somatic weight, a maternal effect on larval production continued to be evident in widow rockfish (Fig. 5d). Relative fecundity increased with maternal size (linear regression with weight: $F_{1,54}=5.295, \mathrm{p}=0.025, \mathrm{r}^{2}=0.13$, power regression with length: $F_{1,54}=7.757, \mathrm{p}=0.007, \mathrm{r}^{2}=0.09$ ) and age (power regression with age: $F_{1,53}=4.464, \mathrm{p}=$ $0.039, \mathrm{r}^{2}=0.08$ ).

There was a positive relationship between maternal size and relative fecundity in yellowtail rockfish (Fig. 5e, linear regression with weight: $F_{1,92}=11.012$, $\mathrm{p}=0.001, \mathrm{r}^{2}=0.11$, linear regression with length: $\left.F_{1,92}=12.440, \mathrm{p}=0.001, \mathrm{r}^{2}=0.12\right)$. There was no significant relationship between relative fecundity and age $\left(F_{1,91}=0.419, \mathrm{p}=0.519\right)$ in yellowtail rockfish. In comparing yellowtail rockfish pre-parturition relative fecundity with previously published data on fish held in laboratory tanks until parturition (Sogard et al. 2008), both groups displayed a positive relationship between relative fecundity and maternal fork length; however, the coefficient of determination was greater for the laboratory study $\left(r^{2}=0.34\right.$, Fig. 5e). The slope of the relationship did not differ between the 2 studies (fixed-effects ANCOVA: $F_{1,106}=0.558$, $\mathrm{p}=0.457$ ), suggesting a similar maternal effect, but the intercept was lower in the laboratory study, suggesting a lower overall fecundity estimate compared to that calculated from pre-parturition fish (fixedeffects ANCOVA: $F_{1,107}=5.616, p=0.02$ ).

In chilipepper, relative fecundity increased with maternal size and age (Fig. 5f), with linear relationships providing the highest correlation for weight $\left(F_{1,171}=43.314, \mathrm{p}<0.001, \mathrm{r}^{2}=0.28\right)$, length $\left(F_{1,171}=\right.$ $\left.60.582, \mathrm{p}<0.001, \mathrm{r}^{2}=0.26\right)$, and age $\left(F_{1,171}=61.210\right.$, $\mathrm{p}<0.001, \mathrm{r}^{2}=0.27$ ).

\section{Egg size comparison among species}

Egg size was significantly different among species (ANCOVA: $F_{2,85}=66.846, \mathrm{p}<0.001$, maternal length covariate: $F_{1,85}=3.377, \mathrm{p}=0.070$, stage covariate: 

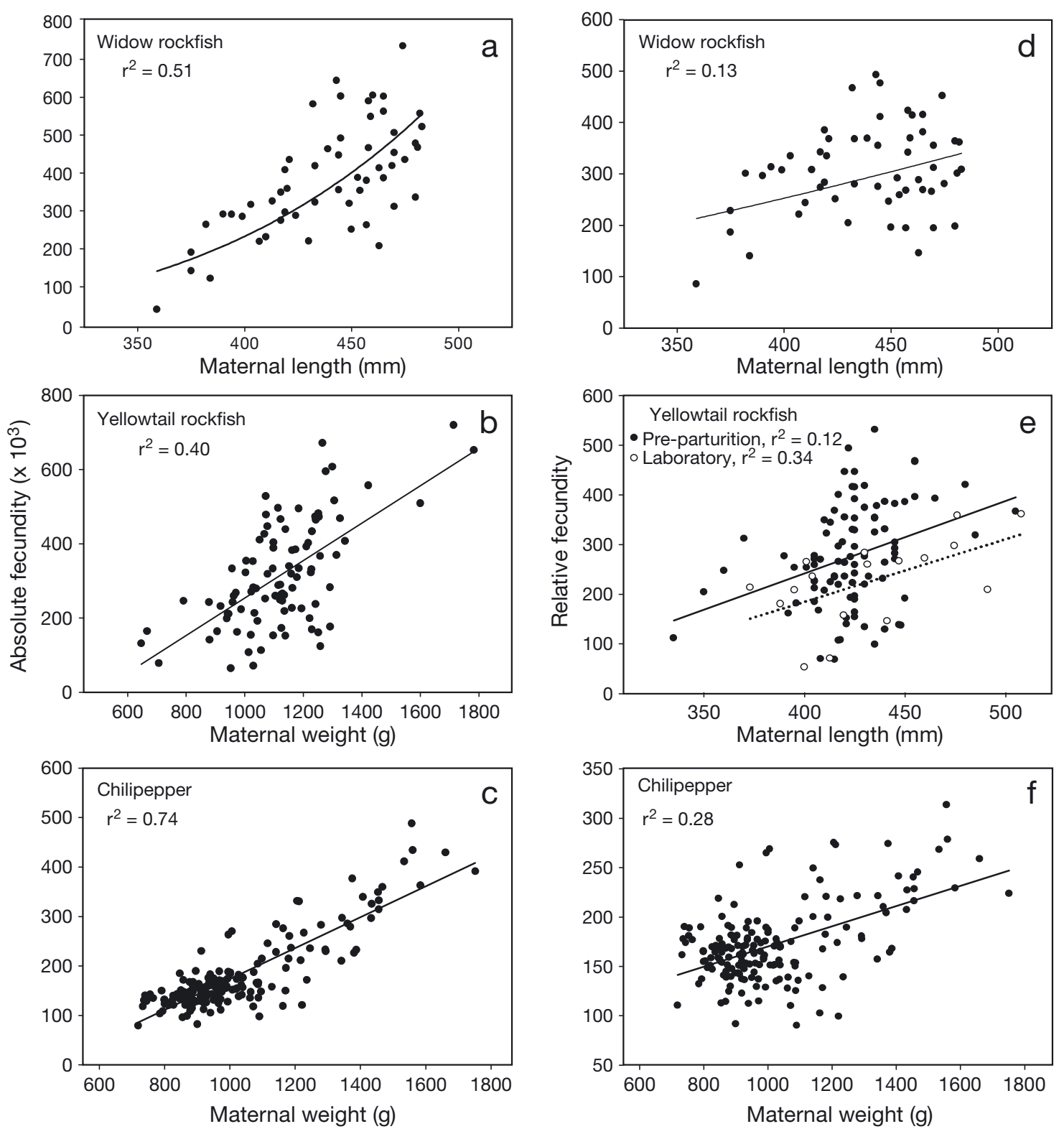

Fig. 5. (a-c) Absolute (no. of larvae) and (d-f) relative (larvae $\mathrm{g}^{-1}$ somatic weight) fecundity versus the maternal factor (length or weight, or age) with the highest significant coefficient of determination for $(\mathrm{a}, \mathrm{d})$ widow rockfish (power function), (b,e) yellowtail rockfish (linear function), and $(\mathrm{c}, \mathrm{f})$ chilipepper (linear function). Dashed line in (e) presents yellowtail rockfish data from laboratory studies for comparison (Sogard et al. 2008)

$\left.F_{1,85}=22.900, \mathrm{p}<0.001\right)$. Chilipepper had larger mean size eggs than both yellowtail and widow rockfishes, which did not differ from each other based on Tukey post hoc analyses. When egg size was plotted versus relative fecundity at a common female size of $450 \mathrm{~mm}$, greater egg size was associated with reduced relative fecundity in chilipepper (mean egg circumference $3.30 \pm 0.05 \mathrm{~mm}$, mean relative fecundity $194 \pm 10.1$ larvae $\mathrm{g}^{-1}$ ) in comparison to that of widow (mean egg circumference $2.60 \pm 0.16 \mathrm{~mm}$, mean relative fecundity $314 \pm 87.5$ larvae $\mathrm{g}^{-1}$ ) and yellowtail (mean egg circumference $2.34 \pm 0.09 \mathrm{~mm}$, mean relative fecundity $314 \pm 50.8$ larvae $\mathrm{g}^{-1}$ ).

\section{Larval quality}

Oil and yolk depletion rates

The 2 forms of energy reserves, yolk and oil globule, were utilized differently during embryogenesis (Fig. 6). Early in development, yolk was utilized at a 


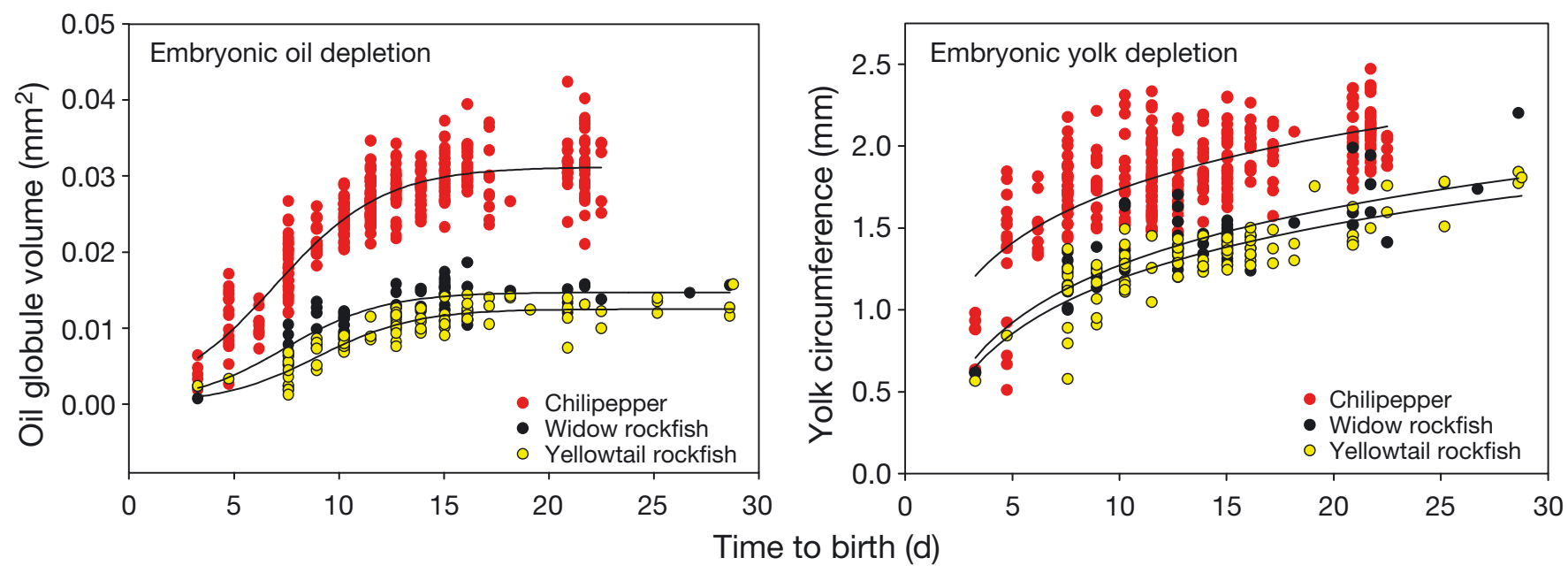

Fig. 6. Energy reserve depletion. Each of the 3 species displayed a sigmoidal trend in the depletion of oil reserves during embryogenesis: chilipepper, $y=0.0312 /\left[1+\mathrm{e}^{-(x-6.9512) / 2.5956}\right]$; widow rockfish, $y=0.0147 /\left[1+\mathrm{e}^{-(x-7.4240) / 2.3289}\right]$; yellowtail rockfish, $y=0.0125 /\left[1+\mathrm{e}^{-(x-8.9894) / 2.3041}\right]$. Yolk reserves depleted in a logarithmic fashion in the 3 species: chilipepper, $y=0.6489+$ $0.4724 \times \ln (x) ;$ widow rockfish, $y=0.1084+0.5054 \times \ln (x) ;$ yellowtail rockfish, $y=0.0813+0.4810 \times \ln (x)$

faster rate than oil, followed by the rapid depletion of both resources beginning around $15 \mathrm{~d}$ prior to parturition. Just prior to parturition, yolk depletion accelerated whereas oil depletion slowed. In all 3 species, yolk depletion curves followed a logarithmic trend with time, whereas oil depletion displayed a sigmoidal trend. Matching their larger egg sizes, chilipepper embryos were provisioned with more oil and yolk than widow and yellowtail rockfishes.

Relationship between maternal age/size and oil globule volume

Oil globule volume was not related to maternal age, length, or weight in widow or yellowtail rockfishes but was weakly correlated in chilipepper, which had a positive relationship between oil globule volume residuals from the depletion curve and maternal weight (linear regression: $F_{1,304}=5.523, \mathrm{p}=$ 0.019, $\mathrm{r}^{2}=0.02$, Fig. 7).

\section{DISCUSSION}

\section{Timing of parturition}

Both methods of analyzing maternal effects on the timing of parturition-macroscopic staging and finescale staging - showed analogous patterns for each species, with a clear trend of older, larger fish releasing larvae earlier than younger, smaller fish in widow and yellowtail rockfish and a bimodal pattern for older chilipepper. Macroscopic staging analysis provided a larger sample size that included stage 2 (unfertilized) and stage 5 (spent) fish and showed the general course of gonadal development for different size classes through time. Fine-scale staging allowed increased precision in estimating the date of parturition but with a reduced sample size. Our estimates of parturition dates based on fine-scale staging relied on the assumption that widow rockfish and chilipepper have similar gestation times to those established for yellowtail rockfish by Eldridge et al. (2002). Few studies have characterized rockfish embryonic development from fertilization through parturition; thus, knowledge of accurate gestation times is limited. Developmental sequence, however, appears to be common in the genus, as observed in studies of yellowtail rockfish (Eldridge et al. 2002), black rockfish Sebastes melanops (Boehlert \& Yoklavich 1984), and kurosoi S. schlegeli (Yamada \& Kusakari 1991), although there were variations in the rate of development because of differences in water temperatures. Despite the much greater resource provisioning of chilipepper embryos compared to yellowtail and widow, the 3 species exhibited a strikingly similar pattern of yolk and oil depletion by developmental stage (Fig. 6, where time to birth is a function of stage). Stage definition generally depends on physical features, such as the appearance of otoliths, and is therefore independent of yolk and oil quantities. This similarity in embryo development among species suggests that the assumption of a common, temperature-dependent gestation time is reasonable, but we were not able to test this assumption with our 

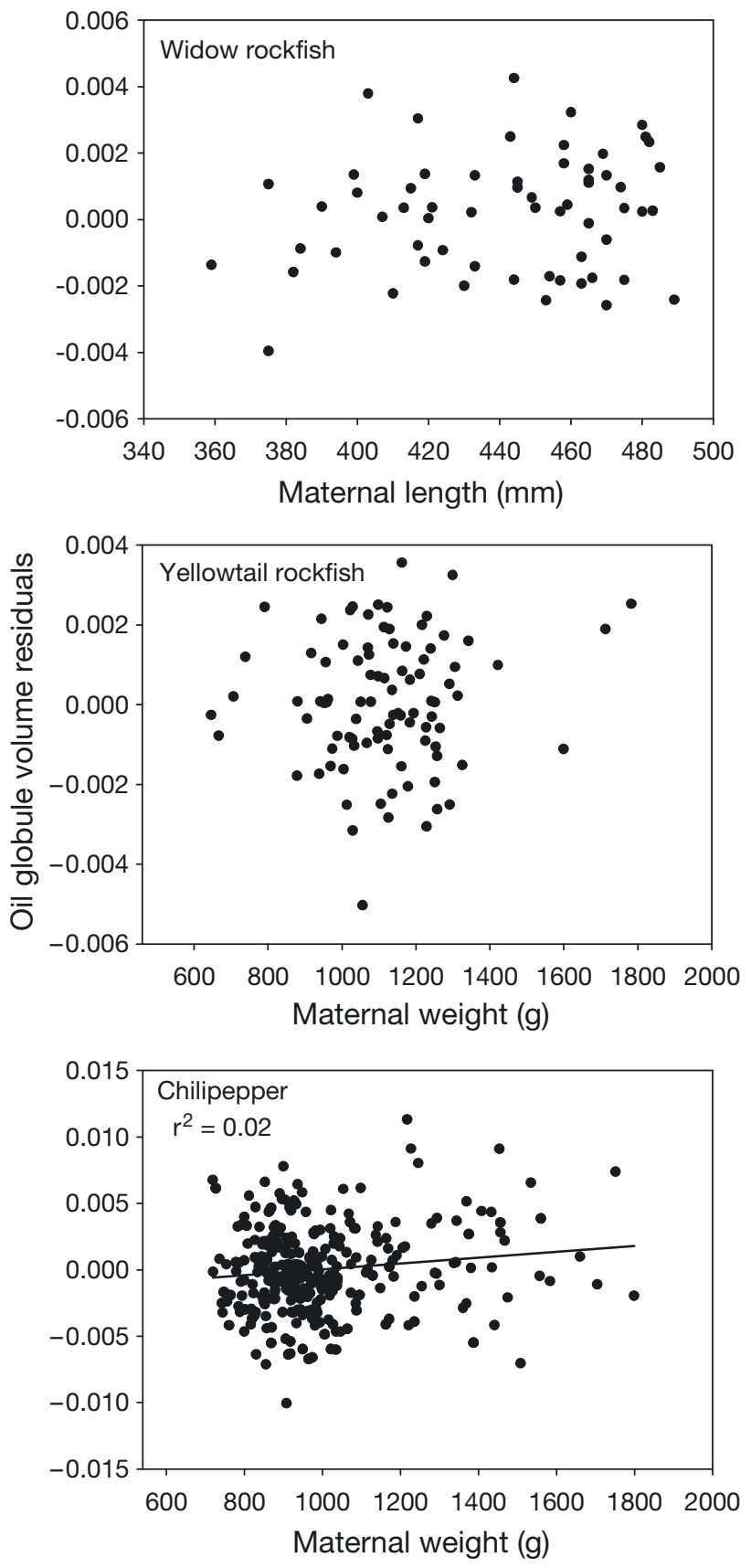

Fig. 7. Maternal influence on oil globule volume. The $y$-axis represents residuals from the sigmoidal depletion curves shown in Fig. 6. The maternal factor with the highest coefficient of determination for each species is shown; the relationship was significant only for chilipepper

data. If the gestation period is longer or shorter than predicted, the estimated dates of parturition would be comparably expanded or compressed, but any maternal effects would remain. Individual variability in gestation period, documented to range between 27 and $33 \mathrm{~d}$ in yellowtail rockfish (Eldridge et al. 2002), can also impact precision in estimates of extrusion date. The extent of individual variability as well as species differences in gestation time need to be addressed in future research.

By giving birth earlier in the season, older, larger yellowtail and widow rockfishes effectively extended parturition at the population level, thus offering an advantage to the population in contending with seasonal environmental variability encountered by newly released larvae in a match-mismatch scenario. At the individual level, this pattern is consistent with the diversified bet-hedging strategy for maternal lineages proposed by Sogard et al. (2008). A pattern of earlier spawning by older, larger females is evident in a phylogenetically diverse range of species (review in Hixon et al. 2013). Age truncation in fish populations, with a consequent shift of reproduction to younger females, has been associated with increased variability in recruitment, potentially a consequence of the restricted period of spawning and increased mismatch with environmental conditions (Hixon et al. 2013).

In contrast to yellowtail and widow rockfish, older chilipepper did not contribute to an extension of the parturition season; the 1999 year class alone spanned the range of observed parturition dates. The bimodal pattern observed in the parturition dates of older chilipepper (Fig. 3) visually suggests multiple parturition within a season; however, we saw no evidence of multiple broods in ovary examination. In a more recent study (Beyer et al. 2014), multiple broods were common in chilipepper collected in a southern population (Santa Barbara Channel) and occurred occasionally in central California populations. Our detection of multiple broods depends on the presence of residual larvae that were not released from the first brood. It is possible that multiple broods occurred in chilipepper during this study but were not detected.

\section{Fecundity}

Older, larger fishes produced more offspring in both absolute and relative terms; thus, the assumption that larval production is a function of female biomass regardless of size structure is inappropriate for these species. In general, fecundity estimates derived in this study were comparable to estimates for the 3 species in other studies (Boehlert et al. 1982, Haldorson \& Love 1991, Eldridge \& Jarvis 1995, Beyer et al. 2014). Likewise, the differences among species, with the reduced absolute fecundity of chilipepper com- 
pared to widow or yellowtail rockfish and the much weaker maternal effect on relative fecundity in chilipepper, were consistent with Haldorson \& Love's (1991) comparisons of relative fecundity at $50 \%$ maturity and at maximum fish size.

Although a significant maternal effect on relative fecundity was observed in all 3 species, there was substantial variability among individual females, suggesting that female age/size only partly determines the allocation of resources to egg production. The success of females in storing energy reserves during the pre-reproductive period potentially plays a major role. For example, Eldridge \& Jarvis (1995) found that yellowtail rockfish collected in Washington had greater mesenteric fat reserves and higher relative fecundity than fish collected in central California. Beyer et al. (2014) found several maternal condition indices correlated with relative fecundity in yellowtail, chilipepper, blackgill Sebastes melanostomus, and speckled rockfish $S$. ovalis. In particular, liver size, as indexed by the hepato-somatic index, appeared to be influential.

Pre-parturition yellowtail rockfish in this study had higher relative fecundity than laboratory-held yellowtail rockfish collected from the same location in the same year but a similar slope for the maternal effect of increasing relative fecundity with increasing female size (Fig. 5c, Sogard et al. 2008). This difference may reflect the different methods used to calculate fecundity. A gravimetric method was used for pre-parturition fish in this study, whereas fecundity of the laboratory fish was estimated by the collection of all released larvae followed by the use of a plankton splitter to create countable subsamples.

\section{Larval quality}

No clear age- or size-related maternal effects were evident on the quantity of lipid provisioning and thus larval quality in the 3 study species. A statistically significant $(p=0.019)$ effect of increased oil globule volume with increasing maternal weight, observed in chilipepper, was weak $\left(\mathrm{r}^{2}=0.02\right)$ and perhaps biologically insignificant (Fig. 7b).

The lack of a maternal effect on larval quality in yellowtail rockfish in this study was contrary to findings for yellowtail rockfish in laboratory studies, which showed a positive relationship between maternal weight and oil globule size at parturition $\left(\mathrm{r}^{2}=\right.$ 0.23, Sogard et al. 2008). Laboratory studies have also found maternal effects on larval quality in black, blue ( $S$. mystinus), and gopher ( $S$. carnatus) rock- fishes (Berkeley et al. 2004a, Sogard et al. 2008). Variations in methodology between laboratory rearing until parturition versus sampling pre-term gravid females could account for this difference. Measurement of larvae at the time of parturition allows more precise estimates of available energy reserves in the oil globule. Examining pre-parturition larvae allows for greater sample sizes; however, drawbacks include possible misestimation in projected time intervals between fine-scale developmental stages and inaccuracies in depletion rate estimations, including lack of accounting for matrotrophic effects.

Small errors in staging have the potential to greatly influence the oil depletion relationship, particularly during the period of rapid catabolism of oil reserves. During the later stages, depletion rates change over a short time period and are difficult to estimate with small sample sizes. A greater sample size of latestage embryos (stages 30 to $33,<7 \mathrm{~d}$ to birth) would be beneficial to critically analyze yolk and oil utilization in stages just prior to parturition.

Although laboratory-rearing studies cannot duplicate the natural environment completely, they provide standardization by reducing the variability from factors associated with field-caught specimens. These include differences in maternal nutrition, activity levels, and water temperature, which can affect developmental rates of embryos. By allowing females to complete gestation, more precise estimates of parturition timing and larval quality can be obtained.

\section{Species differences}

In this study, variability in reproductive strategies among 3 shelf rockfish species was observed, with an apparent trade-off between egg size and fecundity. Chilipepper had the largest egg size and yolk and oil reserves and the lowest absolute and relative fecundity, whereas the reverse pattern was observed for both widow and yellowtail rockfishes. Beyer et al. (2014) also found the mass of chilipepper eggs/larvae to be greater than that of yellowtail at all embryonic stages. Larger larval size at parturition may aid in survivorship because of increased motility for escaping prey and capturing food, while the greater energy reserves in the larger oil globule provide resistance to starvation (Fisher et al. 2007). Several life history traits distinguish chilipepper from widow and yellowtail rockfish (Table 2). Chilipepper tend to be more demersal, their parturition season begins earlier in the winter, they have a shorter lifespan, and they are capable of producing multiple broods. Interestingly, speckled 
rockfish Sebastes ovalis also have low fecundity but large egg size and, like chilipepper, are multiple brooders, begin parturition early, and have a comparable life span of about $34 \mathrm{yr}$ (Beyer et al. 2014). These differences in life history may relate to the importance of quality over quantity for chilipepper larvae.

\section{Conclusions}

Widow rockfish, yellowtail rockfish, and chilipepper each exhibited a positive age- or size-related maternal effect on 1 or more reproductive metrics in this study, extending this pattern previously reported in nearshore species (Berkeley et al. 2004a, Bobko \& Berkeley 2004, Fisher et al. 2007, Sogard et al. 2008, Rodgveller et al. 2012) to deeper-dwelling rockfishes. The strength and pattern of such maternal effects differ among species, potentially reflecting differences in life histories. These results further support the suggested benefits of preserving age structure in rockfishes as well as accounting for differences in life histories among species. Numerous rockfish species have experienced age/size truncation because of fishing pressure on these slow-growing, late-maturing fishes (Parker et al. 2000, Berkeley et al. 2004b, Harvey et al. 2006). A recent review by Hixon et al. (2013) demonstrates that positive maternal effects on reproductive capacity are common in exploited fish species and that extensive age truncation results in widespread diminished ability to buffer against temporal environmental variability. The effects of continual size/age truncation may be phenotypic and reversible or they may induce evolutionary responses, with less plastic shifts toward reduced growth rate, age at maturity, body size, and productivity (Conover \& Munch 2002, Law 2007). Management options that protect older fish, accounting for the phenology of parturition and oceanic regime, can enhance conditions for the successful rebuilding of species in the genus Sebastes.

Acknowledgements. We thank G. Cailliet, S. Parker, and L. Allen for their advice and helpful comments. We appreciate R. Powers of the New Sea Angler and the efforts of the volunteer fisherman who assisted in rockfish collection. $\mathrm{N}$. Kashef and N. Parker provided valuable assistance in field work and fish processing. L. Jennings, T. Archer, and S. Brown assisted with fecundity estimation. We thank J. Field for a thorough review of an earlier draft of the paper. We are grateful to D. Pearson for help with ageing. Financial support for this study was provided by California Sea Grant project R/MLPA-03 to S.A.B., and S. Parker, entitled 'Using life history characteristics to determine optimum placement of marine reserves', and by NOAA Fisheries.

\section{LITERATURE CITED}

Bagenal TB, Braum E (1978) Eggs and early life history. In: Bagenal T (ed) Methods for assessment of fish production in fresh waters, Blackwell Scientific, Oxford, p 165-201

Beamish RJ, Chilton DE (1982) Preliminary evaluation of a method to determine the age of sablefish (Anoplopoma fimbria). Can J Fish Aquat Sci 39:277-287

Berkeley SA (2006) Pacific rockfish management: Are we circling the wagons around the wrong paradigm? Bull Mar Sci 78:655-668

> Berkeley SA, Chapman C, Sogard SM (2004a) Maternal age as a determinant of larval growth and survival in a marine fish, Sebastes melanops. Ecology 85:1258-1264

> Berkeley SA, Hixon MA, Larson RJ, Love MS (2004b) Fisheries sustainability via protection of age structure and spatial distribution of fish populations. Fisheries 29: 23-32

Beyer SG, Sogard SM, Harvey CJ, Field JC (2014) Variability in rockfish (Sebastes spp.) fecundity: species contrasts, maternal size effects, and spatial differences. Environ Biol Fishes, doi: 10.1007/s10641-014-0238-7

Blaxter JHS (1969) Development: eggs and larvae. In: Hoar WS, Randall DJ (eds) Fish physiology, Vol 3. Academic Press, New York, NY, p 177-252

Bobko SJ, Berkeley SA (2004) Maturity, ovarian cycle, fecundity, and age-specific parturition of black rockfish (Sebastes melanops). Fish Bull 102:418-429

Boehlert GW, Yoklavich MM (1984) Reproduction, embryonic energetics, and the maternal-fetal relationship in the viviparous genus Sebastes (Pisces: Scorpaenidae). Biol Bull 167:354-370

Boehlert GW, Barss WH, Lamberson PB (1982) Fecundity of the widow rockfish, Sebastes entomelas, off the coast of Oregon. Fish Bull 80:881-884

Cailliet GM, Andrews AH, Burton EJ, Watters DL, Kline DE, Ferry-Graham LA (2001) Age determination and validation studies of marine fishes: Do deep dwellers live longer? Exp Gerontol 36:739-764

> Cailliet GM, Smith WD, Mollet HF, Goldman KJ (2006) Age and growth studies of chondrichthyan fishes: the need for consistency in terminology, verification, and growth function fitting. Environ Biol Fishes 77:211-228

Conover DO, Munch SB (2002) Sustaining fisheries yields over evolutionary time scales. Science 297:94-96

Cushing DH (1990) Plankton production and year-class strength in fish populations: an update of the match/ mismatch hypothesis. Adv Mar Biol 26:249-293

de Bruin JP, Gosden RG, Finch CE, Leaman BM (2004) Ovarian aging in two species of long-lived rockfish, Sebastes aleutianus and S. alutus. Biol Reprod 71:1036-1042

Dick EJ (2009) Modeling the reproductive potential of rockfishes (Sebastes spp.). PhD thesis, University of California, Santa Cruz

- Eldridge MB, Jarvis BM (1995) Temporal and spatial variation in fecundity of yellowtail rockfish. Trans Am Fish Soc 124:16-25

- Eldridge MB, Norton EC, Jarvis BM, MacFarlane RB (2002) Energetics of early development in the viviparous yellowtail rockfish. J Fish Biol 61:1122-1134

- Fisher R, Sogard SM, Berkeley SA (2007) Trade-offs between size and energy reserves reflect alternative strategies for optimizing larval survival potential in rockfish. Mar Ecol Prog Ser 344:257-270

Gunderson DR, Calahan P, Goiney B (1980) Maturation and 
fecundity of four species of Sebastes. Mar Fish Rev 42: 74-79

Haldorson L, Love M (1991) Maturity and fecundity in the rockfishes, Sebastes spp., a review. Mar Fish Rev 53: 25-31

Harvey CJ, Tolimieri N, Levin PS (2006) Changes in body size, abundance and energy allocation in rockfish assemblages of the northeast Pacific. Ecol Appl 16:1502-1515

Hixon MA, Johnson DW, Sogard SM (2013) BOFFFFs: on the importance of conserving old-growth age structure in fishery populations. ICES J Mar Sci, doi: 10.1093/ icesjms/fst200

Laidig TE, Pearson DE, Sinclair LL (2003) Age and growth of blue rockfish (Sebastes mystinus) from central and northern California. Fish Bull 101:800-808

Law R (2007) Fisheries-induced evolution: present status and future directions. Mar Ecol Prog Ser 335:271-277

Leaman BM, Beamish RJ (1984) Ecological and management implications of longevity in some northeast Pacific groundfishes. Bulletin INPFC 42:85-97

Leaman BM, Nagtegaal DA (1987) Age validation and revised natural mortality rate for yellowtail rockfish. Trans Am Fish Soc 116:171-175

Lenarz WH (1987) Ageing and growth of widow rockfish. In: Lenarz WH, Gunderson DR (eds) Widow rockfish: proceedings of a workshop, Tiburon, California, December 11-12, 1980. NOAA Tech Rep NMFS 48, p 31-35

Longhurst A (2002) Murphy's law revisited: longevity as a factor in recruitment to fish populations. Fish Res 56: 125-131

Love M, Yoklavich M, Thorsteinson L (2002) The rockfishes of the Northeast Pacific. University of California Press, Berkeley, CA

Lucero Y (2008) Maternal effects and time to recovery. Bull Mar Sci 83:217-234

Lucero Y (2009) A multivariate stock-recruitment function for cohorts with sympatric subclasses: application to

Editorial responsibility: Thomas Turner,

Albuquerque, New Mexico, USA maternal effects in rockfish (genus Sebastes). Can J Fish Aquat Sci 66:557-564

MacGregor JS (1970) Fecundity, multiple spawning, and description of the gonads in Sebastodes. US Fish Wildl Serv Spec Sci Rep Fish 596

Nichol DG, Pikitch EK (1994) Reproduction of darkblotched rockfish off the Oregon coast. Trans Am Fish Soc 123: 469-481

- Norton EC, MacFarlane RB (1999) Lipid class composition of the viviparous yellowtail rockfish over a reproductive cycle. J Fish Biol 54:1287-1289

> Parker SJ, Berkeley SA, Golden JT, Gunderson DR and others (2000) Management of Pacific rockfish. Fisheries 25:22-30

Pearcy WG (1992) Movements of acoustically-tagged yellowtail rockfish Sebastes flavidus on Heceta Bank, Oregon. Fish Bull 90:726-735

- Pereyra WT, Carvey FE Jr, Pearcy WG (1969) Sebastodes flavidus, a shelf rockfish feeding on mesopelagic fauna, with consideration of the ecological implications. J Fish Res Board Can 26:2211-2215

Rodgveller CJ, Lunsford CR, Fujioka JT (2012) Effects of maternal age and size on embryonic energy reserves, developmental timing, and fecundity in quillback rockfish (Sebastes maliger). Fish Bull 110:36-45

Sogard SM, Berkeley SA, Fisher R (2008) Maternal effects in rockfishes Sebastes spp.: a comparison among species. Mar Ecol Prog Ser 360:227-236

Spencer PD, Dorn MW (2013) Incorporation of weightspecific relative fecundity and maternal effects in larval survival into stock assessments. Fish Res 138:159-167

Wyllie Echeverria T (1987) Thirty-four species of California rockfishes: maturity and seasonality of reproduction. Fish Bull 85:229-250

> Yamada J, Kusakari M (1991) Staging and the time course of embryonic development in kurosoi, Sebastes schlegeli. Environ Biol Fishes 30:103-111

Submitted: August 7, 2013; Accepted: March 13, 2014 Proofs received from author(s): May 12, 2014 